\title{
Prática e teoria no desenvolvimento: questão da tomada de consciência
}

\author{
Adrián Oscar Dongo Montoya \\ Universidade Estadual Paulista Júlio de Mesquita Filho - Marília - SP - Brasil
}

\begin{abstract}
Resumo
O estudo psicológico do desenvolvimento moral, assim como da vida afetiva e intelectual, coloca em evidência a necessidade de estabelecer as relações entre a ação prática da criança e a reflexão dela sobre suas próprias ações e dos outros indivíduos. Porém, analisar essas relações exige levar em conta o processo que poderá torná-los inteligíveis: a tomada de consciência. Neste trabalho, analisaremos essas questões a partir de algumas perguntas básicas que se referem ao desenvolvimento moral: Como a criança pensa as regras morais na própria prática dos atos e fora desses? Existe correspondência entre os julgamentos morais e a prática moral da criança? Na formação da moral heterônoma e da moral autônoma, as práticas e juízos morais são os mesmos? Os juízos resultam da tomada de consciência das práticas morais? Neste estudo, destacaremos esses problemas e apontaremos vias de solução que se mostram na pesquisa psicogenética de Jean Piaget.
\end{abstract}

Palavras-chave: conscientização; relação teoria-prática; desenvolvimento moral.

\section{Practice and theory in the moral development: question of awareness}

\begin{abstract}
The psychological study of moral development, as well as of affective and intellectual life, highlights the need to establish relationships between the child's practical action and reflection on his or her own actions and those of other individuals. However, analyzing these relationships requires taking into account the process that may make them intelligible: awareness. In this work, we will analyze these questions from some basic questions that refer to moral development: How does the child think the moral rules in the practice of the acts themselves and outside of them? Is there a correspondence between the moral judgments and the moral practice of the child? In the formation of heteronomous morality and autonomous morality, are moral practices and judgments the same? Do judgments result from the awareness of moral practices? In this study, we will highlight these problems and point out ways of solution that are shown in the psychogenetic research of Jean Piaget.
\end{abstract}

Keywords: cognition; relation between theory and practice; Moral development.

\section{Práctica y teoría en el desarrollo moral: cuestión de la toma de consciencia}

\section{Resumen}

El estudio psicológico del desarrollo moral, así como de la vida afectiva e intelectual, pone de relieve la necesidad de establecer las relaciones entre la acción práctica del niño y la reflexión de él sobre sus propias acciones y de los otros individuos. Sin embargo, analizar esas relaciones exige llevar en cuenta el proceso que los podrá tornar inteligibles: a la toma de consciencia. En este estudio, se analizaron esas cuestiones a partir de algunas preguntas básicas que se refieren al desarrollo moral: ¿Cómo el niño piensa las reglas morales en la propia práctica de los actos y fuera de estos? ¿Hay correspondencia entre los juzgamientos morales yla práctica moral del niño? En la formación de la moral heterónoma y de la moral autónoma, ¿las prácticas y juicios morales son iguales? ¿Los juicios resultan de la toma de consciencia de las prácticas morales? En este estudio, se destacó esos problemas y se apuntó caminos de solución que se muestran en la investigación psicogenética de Jean Piaget. Palabras clave: concientización; relación teoría-práctica; desarrollo moral. 


\section{Introdução}

Apesar de Piaget ter escrito pouco sobre a vida moral - existe um único livro (1994) e alguns artigos (1927, 1930, 1931, 1934, 1998a, 1998b) sobre o assunto - não podemos negar a enorme importância da moral na obra dele. Embora a elaboração de uma teoria da moral seja um projeto inacabado, os trabalhos deixados por esse autor evidenciam um corpo teórico coerente sobre tal assunto. Autores como Freitag $(1990,1991,1992)$ procuram evidenciar a intenção de Piaget de formular uma teoria da moral e do conhecimento; outros, como Ducret (1984), Vonèche (1992), Vidal (1994) e Freitas (2003), reconhecem esse objetivo já na juventude de Jean Piaget, exposto no seu ensaio autobiográfico Recherche (Piaget, 1918).

Segundo Ducret (1984) e Freitas (2003), Piaget, nesse ensaio, tem a intenção de formular uma teoria da moral a partir de certas convicções biológicas e filosóficas fundamentais. Essas convicções estão relacionadas à concepção sistêmica e dinâmica da organização da vida e do conhecimento. Sistêmica, no sentido das relações entre as partes e o todo, em todos os níveis e âmbitos da organização; dinâmica, no sentido de entender a diferenciação e integração entre os equilíbrios reais e ideais. Os equilíbrios reais são instáveis e tendem para um equilíbrio ideal ou estável. Desse modo, o desenvolvimento dos sentimentos morais, assim como os conhecimentos, deverá ser explicado em função desse movimento.

Nessa perspectiva o jovem Piaget se propõe tratar a moral na sua natureza específica. Assim, para fundar a sua teoria da moral, o autor deverá buscar as suas raízes em sentimentos contrários ao utilitarismo e ao amoralismo, ou seja, no altruísmo (Piaget, 1918).

As origens do altruísmo deve-se buscar nas primeiras condutas e sentimentos da criança e observar a sua evolução até se constituírem os fundamentos da moral do bem. O grande problema é que entre as condutas e sentimentos iniciais e a moral do bem propriamente dita intervém a autoridade adulta, que produz um "curto-circuito"na sua trajetória evolutiva; além disso, o problema é vencer as dificuldades da sua evolução interna que consiste em superar a sua natureza estrutural inicial para constituir outra qualitativamente diferente.

Assim, visando compreender o sistema teórico de Piaget sobre o desenvolvimento moral, nos deteremos na análise da sua obra psicológica principal para observar a tese da continuidade funcional e da transformação estrutural das ações e sentimentos primitivos da criança; noutros termos, observar como as ações e sentimentos iniciais altruístas se tornam noções e sentimentos conscientes, estruturalmente diferentes. Nesse processo de transformação, destacaremos o papel que cumpre o mecanismo psicológico da tomada de consciência.

A teoria de Piaget sobre o desenvolvimento moral nem sempre foi compreendida e aceita pelos seus continuadores e críticos. No que diz respeito à relação ação e consciência, comportamento e representação, as divergências ainda são mais acentuadas. Na pesquisa bibliográfica realizada por Lemos de Souza e Vasconcelos (2009), que focaliza a relação juízo e ação moral nas teorias da moralidade, se evidenciam diferenças e até oposições por parte dos seus seguidores. Assim, para um dos seus seguidores mais destacados, Lawrence Kohlberg, a ação não precede o juízo e a tomada de consciência não cumpre um papel central nos níveis de moralidade mais altos. De igual modo, para muitos dos seus críticos, a relação existente entre ação e consciência é ainda mais controvertida.

Contudo, embora a relação entre ação e consciência moral seja controvertida para seus seguidores e críticos, cremos que a inteligibilidade dessa relação ganha significado quando inserida num sistema teórico.

Para cumprir com nosso objetivo, nos apoiamos basicamente na obra central de Piaget "O julgamento moral na criança"(1932,/1994) e outros artigos complementares sobre o tema (1927, 1930, 1931, 1934, 1998a, 1998b). Além disso, nos apoiaremos nas pesquisas mais atuais de Piaget sobre os processos e mecanismos responsáveis pelo desenvolvimento psicológico, como a "Tomada de Consciência” (Piaget, 1977), «Fazer e Compreender» (Piaget, 1978) e «Abstração Reflexionante» (Piaget, 1995). Artigos e trabalhos de outros autores contribuíram também para nossas conjecturas, como os trabalhos de La Taille (2006), Bronzatto e Camargo (2010), Conti (2015).

A questão da tomada de consciência, na teoria de Piaget, é um assunto de grande importância que mereceria maiores estudos nos diferentes campos do comportamento humano, contudo ela mereceu pouca atenção na pesquisa psicológica, como o próprio Piaget coloca em seu estudo mais atual sobre essa questão (Piaget, 1974/1977). Para ele, a tomada de consciência é um campo de pesquisa bem vasto, mas ainda pouco conhecido, embora de grande importância para a Psicologia e para a Epistemologia.

Em outras palavras, os psicólogos interessarem-se, sobretudo, por saber em que ocasiões há ou não tomada de consciência, mas negligenciaram demasiadamente a outra questão, que lhe é complementar e consiste em estabelecer "como" ela se processa. Disto deveremos ocupar-nos com o mesmo empenho (Piaget, 1974/1977, p.11).

A questão da tomada de consciência, na teoria de Piaget, envolve a relação entre a prática e teoria e transcende aos estudos sobre a vida moral. Em virtude disso, no estudo sobre "O Juízo moral na criança"(1932/1994), coloca um problema que pode ser formulado nos seguintes termos: o pensamento verbal ou teórico - o pensamento que atua sobre representações evocadas fazendo uso da linguagem e não sobre coisas que o sujeito age e percebe diretamente - consiste numa tomada de consciência do pensamento espontâneo, com todas as deformações sistemáticas que de fato ocorrem, ligado à prática ou ao pensamento verbal não mantém nenhuma relação com essa última?

Segundo Piaget, esse problema é de extrema importância para toda a psicologia humana, na medida em que 
o homem éum fazedor de discursos. No discurso, as suas palavras exprimem as suas ações ou não têm relação com esta? O estudo da criança conduz à mesma questão geral: o que éo pensamento verbal da criança em relação ao seu pensamento concreto e ativo?

O estudo na criança alcança destaque na medida em que tal questão é de grande importância teórica para a vida psicológica e social humana. Com efeito, no campo filosófico Piaget (1932/1994, p.96) lembra duas concepções opostas importantes: aqueles que defendem uma relação entre a reflexão moral e a prática (quer a primeira sirva de origem a esta, quer a reflexão constitua uma tomada de consciência da ação) e aqueles que defendem o contrário, de que existiriam ações lógicas ou não lógicas (instintivas ou afetivas) independentes dos discursos. Para esta segunda concepção, um palavreado oco se acrescentaria a essas ações: seriam as teorias morais que não teriam relação com a prática.

O que dirão os estudos junto às crianças em relação a essa questão teórica fundamental? Os julgamentos verbais das crianças sobre faltas morais feitas por sujeitos hipotéticos, relatadas através de histórias, têm relação com suas ações ou constituem um palavreado sem relação com as ações efetivas? Noutros termos, os julgamentos da criaça a respeito das transgressões das regras morais, feitas por seus semelhantes, correspondem ou não aos julgamentos feitos na prática dessas regras? Os resultados da pesquisa sobre as regras do jogo realizada por Piaget (1932/1994) apontam para uma correspondência - de nenhum modo simples - entre os julgamentos teóricos e a prática moral. O problema que se coloca a seguir é: Qual a natureza dessa relação e como o sujeito toma consciência das relações exercidas na prática moral?

Para isso, a pergunta básica que coloca Piaget não é saber apenas como a criança pratica sua moral, mas como julga o bem ou o mal na própria prática dos atos e fora deles. Noutros termos, se os julgamentos de valor enunciados no decorrer dos interrogatórios sobre os atos de outras crianças hipotéticas correspondem ou não às avaliações ocorridas durante a própria ação prática.

No campo intelectual, Piaget (1945/1973b; 1936/1987) mostra que o pensamento verbal está em atraso em relação aos esquemas ou "operações" construídos no plano da ação, os quais serão reconstruídos no plano da representação. Nesse processo, antigas dificuldades, já vencidas no plano da ação prática, reaparecem ou simplesmente subsistem no plano verbal. Por isso, existem discrepâncias e defasagens entre as fases da construção verbal e as fases da construção prática. No campo moral, é possivel que existam desvios e atrasos entre o julgamento de valor teórico e as avaliações concretas da criança. Será que o primeiro consiste numa tomada de consciência adequada em relação às segundas?

Existem crianças que no plano verbal ou teórico não levam em conta as intenções para avaliar os atos dos outros (responsabilidade objetiva), mas quando lhes perguntamos assuntos pessoais e vividos, levam em conta as intenções em jogo. É possível, então, que, em tal caso, o juízo moral teórico esteja simplesmente atrasado em relação ao juízo moral prático e que corresponde a um estágio atualmente ultrapassado no plano da própria ação; contudo, é possível também que não exista nenhuma relação. Nesse caso, a teoria moral da criança será um simples palavreado, sem relação com suas avaliações concretas. Assim, neste último caso, o pensamento da criança, até 10 ou 12 anos, não seria essencialmente uma repetição ou uma deformação do pensamento do adulto, sem relação com as avaliações morais reais da criança na prática de sua conduta?

As pesquisas de Piaget sobre o jogo de regras, especificamente o jogo de bolinhas, revela que entre a ação e a teoria existe uma correspondência definida, embora não simples. À prática egocêntrica da regra, que segue paralela a um sentimento de respeito unilateral pelo mais velho e pelo adulto, corresponde um juízo teórico que faz da regra uma realidade mística e transcendente. À prática racional da regra, que segue paralela ao respeito mútuo, corresponde um juízo teórico que atribui à regra uma característica de inteira autonomia.

A pesquisa de Conti (2015) verifica as hipóteses de Piaget sobre as relações entre a prática e a consciência moral no jogo de regras junto a um grupo de crianças brasileiras utilizando o jogo de "bola queimada". Mostra que a forma elementar de entender a regra no plano da reflexão não éum simples palavreado, mas, sim, reflete aquilo que ela pensa e sente nas atividades práticas iniciais (respeito unilateral); mostra que o conhecimento das regras do jogo na prática se encontra mais evoluído que no plano do pensamento verbal e da reflexão teórica; evidencia que os atrasos da reflexão teórica sobre as regras do jogo obedecem a deformações inerentes aos mecanismos de reflexão e ao fato de encontrar dificuldades já vencidas no campo da prática (levar em conta as intenções dos parceiros do jogo). Essa pesquisa evidencia, finalmente, que embora no começo exista um certo descompasso entre a prática e a teoria, no final do processo essa relação se equilibra na medida em que progridem as relações de cooperação. Na medida em que os obstáculos estruturais são vencidos - egocentrismo e ação da coação - sobre os afeitos da cooperação, a necessidade da reciprocidade se afirma no plano da consciência.

No que se refere ao domínio da moral propriamente dito, Piaget formula a seguinte hipótese: o juízo verbal ou teórico da criança corresponde, em linhas gerais, aos juízos concretos e práticos que ela pode fazer, no decorrer de suas ações, durante os anos precedentes ao interrogatório. Assim, o pensamento verbal teórico, mesmo estando em atraso em relação ao pensamento prático, se relaciona de alguma maneira com os estágios já ultrapassados desse pensamento prático (formas primárias e elementares).

Mas, se o pensamento verbal teórico, que reflete os juízos de responsabilidade objetiva e a moral do dever, prolonga ações práticas de respeito unilateral, o pensamento verbal teórico, que se refere à responsabilidade subjetiva e àmoral do bem, prolonga que tipos de ações práticas? Trata-se de um simples palavreado ou psitacismo que se acrescenta àmoral do dever? 
Piaget coloca essa questão levando em conta a contribuição decisiva de Claparède sobre o processo de tomada de consciência. Assim, para Piaget, tomar consciência das verdadeiras bases morais que conduzem àautonomia se encontra limitado pelos efeitos do egocentrismo e a coação social. Esse processo não é restrito àcriança; no adulto, é de uma importância considerável no mecanismo da vida social.

É preciso frisar que a questão da relação entre teoria e prática no campo moral não se confunde com a relação entre teoria e prática no campo intelectual. Embora apresentem processos análogos e solidários, um não se reduz ao outro, pois as ações e relações que envolvem são diferentes: o campo intelectual visa a normas lógicas abstraídas das coordenações gerais das ações feitas sobre os objetos (conteúdos experimentais); o campo moral visa a normas morais ligadas a ações e coordenações que exigem uma afeição mútua. Por isso, o processo construtivo do segundo é muito mais difícil que o primeiro. As regras morais transmitidas pelo adulto geram um fenomenismo e egocentrismo difícil de ser vencido, pois a ordem do mundo para a criança se define pela obediência mística ao adulto, e compreendê-lo exige estruturar a realidade segundo níveis de complexidade e profundidade cada vez maiores.

\section{Relação entre prática e teoria na formação da moral do dever}

A pesquisa de Piaget sobre a coação e o realismo moral mostra que as primeiras formas de reflexão moral da criança sobre os desajeitamentos, o roubo e a mentira apresentam uma caraterística básica: as ações das personagens relatadas nas histórias são julgadas a partir das suas consequências materiais e do caráter literal da regra moral transmitida (ao pé da letra). A criança não leva em conta as características e as intenções dos personagens que transgridem ou ocasionam as faltas morais. Esse modo de julgamento se define como responsabilidade objetiva, a qual é causada pelo encontro da coação do adulto e o egocentrismo infantil (encontro que gera o respeito unilateral).

Os resultados dessa pesquisa evidenciam processos que, sem serem estágios propriamente ditos, caracterizam grandes etapas do desenvolvimento moral: o pensamento teórico da criança obedece, num primeiro momento, a princípios provenientes do respeito unilateral (moral da heteronomia e da responsabilidade objetiva) e depois a princípios provenientes do respeito mútuo - moral da interiorização da regra e da responsabilidade subjetiva (moral da autonomia).

Neste estudo, não adentraremos a caraterização das etapas nem nas explicações sobre os fatores individuais e sociais que intervêm na formação do realismo moral e da responsabilidade objetiva, mas procuraremos entender a relação entre os julgamentos e as ações concretas das crianças. Os julgamentos verbais são apenas um palavreado sobreposto às suas ações, sem vínculo causal com elas, ou se trata de um pensamento que corresponde, de maneira adequada ou deformada, às ações e pensamentos anteriores? A responsabilidade objetiva, evidenciada nos julgamentos teóricos, é um palavreado ou representa, pelo contrário, o prolongamento dos pensamentos feitos na vida prática das crianças pequenas?

O problema que subsiste é o seguinte: A que correspondem esses resultados verbais teóricos em relação ao pensamento moral efetivo da criança? As reflexões morais feitas espontaneamente pela criança ou diante de histórias apresentadas pelo pesquisador constituem ou não o prolongamento de algum pensamento efetivo?

Para Piaget, os resultados da pesquisa sobre os valores morais, como o roubo, a mentira e o desajeitamento, evidenciam que a reflexão teórica da criança se inicia pela manifestação da responsabilidade objetiva e corresponde, numa certa medida, a fatos morais reais vividos previamente. Os resultados revelam também que a reflexão moral teórica, ao expressar a responsabilidade objetiva, consiste também na manifestação de um estado -bastante prolongado - que resiste a sua superação. Como as relações do pensamento com a ação estão longe de ser tão simples, como se crê habitualmente, o autor insiste sobre a necessidade de compreender melhor a verdadeira perspectiva onde situar tais resultados. Para isso, os situa no processo da tomada de consciência das normas morais. Em primeiro lugar, o realismo moral, embora fosse de formação secundária em relação à simples aspiração do bem da criança pequena, constitui a primeira noção da qual o pensamento moral toma consciência quando dos seus ensaios de reflexão e de formulação. Isso estaria de acordo com a formulação de Claparède sobre o processo da tomada de consciência: o que é primeiro na ordem da ação está em último lugar na ordem da tomada de consciência. Desse modo, se o realismo moral aparece como um fenômeno primitivo sobre o plano verbal, não está provado que seja assim no plano da própria atividade prática, pois nesse plano a necessidade de afeição recíproca da criança pode já estar presente na sua vida moral. Na concepção de Piaget, a noção do bem, que aparece ulterior à noção do puro dever, constitui a condição primeira da vida moral verdadeira: a necessidade de afeição recíproca. Em segundo lugar, a tomada de consciência constitui um processo de reconstrução das construções já feitas no plano da ação prática. Por isso, ela estaria necessariamente em atraso em relação à atividade propriamente dita. Em consequência, se o realismo moral no plano da reflexão corresponde a uma realidade própria à ação moral, essa realidade já não será possível encontrá-la no nível da reflexão, mas sim bem antes, no plano da prática. Assim, a responsabilidade objetiva pode muito bem estar ultrapassada há muito tempo no plano da ação, mas subsistir, todavia, no plano do pensamento teórico.

Procurando provar esse pressuposto, o autor mostra, no decorrer dos primeiros anos do desenvolvimento moral da criança, fatos de realismo moral e de responsabilidade objetiva, os quais correspondem ulteriormente a fenômenos que se têm observado no plano verbal.

$\mathrm{O}$ autor mostra três exemplos relacionados com situações de aprendizagem de asseio, de prescrições alimen- 
tares e de desajeitamento, que evidenciam quanto é vivaz e espontânea na criança pequena (2 a 3 anos) a avaliação objetiva da responsabilidade. Aliás, é surpreendente que, mesmo em ambientes onde se cultiva por princípio a autonomia da consciência infantil, as ordens recebidas conduzam a um realismo moral evidente. A regra emanando dos pais provoca uma consciência do dever, contra a qual as atenuações ulteriores dos próprios pais nada conseguem momentaneamente.

J., com um ano, onze meses e vinte e oito dias, está acamada e tomou purgante, de cujos efeitos a avisamos. Apesar das precauções de sua mãe, destinadas precisamente a evitar qualquer reação de vergonha ou de culpa, J. fica muito impressionada quando o purgante fez efeito. Ficou com uma expressão sentida (lágrimas nos olhos, boca caída) e demonstrou manifestamente os mesmos sentimentos que teria se o fato lhe tivesse acontecido em circunstâncias normais e por causa de sua negligência (Piaget, 1932/1994, p. 143).

J., aos dois anos, dez meses e sete dias, não está bem, e sua mãe tem impressão que a tigela de legumes habitual é demais para ela. Efetivamente, após alguns bocados, J. manifesta um enfado visível, mas procura terminar a tigela, porque essa é a regra. Acham melhor dispensá-la, mas ela persiste em seu pensamento, ainda que não tenha nenhuma vontade de comer. Quando Ihe é dado um bocado, não pode engoli-lo; porém, quando se Ihe retira a tigela, reclama-a de novo, como se houvesse culpa em não terminá-la. Retiramna definitivamente, tranquilizando-a (afirmando-lhe que isto não é culpa sua, que em certos dias temos menos fome que em outros, etc.) Apesar dessas precauções da mãe, J. põe-se a chorar. Uma vez consolada, continua a apresentar sinais de remorso, promete dormir bem, etc. (Piaget, 1932/1994, p. 144).

J., aos dois anos e meio, brinca com uma concha que Ihe emprestei. Sendo a concha muito frágil, quebra-se na primeira queda. J. fica consternada, e encontro uma dificuldade enorme para persuadi-la que não foi culpa sua (Piaget, 1932/1994, p.145).

Esses exemplos mostram claramente que durante os primeiros anos, a coação inevitável do adulto - por mais atenuada que seja, como éo caso de J. - provoca necessariamente um certo realismo moral, mais ou menos acentuado.

Desse modo, para Piaget, o realismo moral observado mais tarde no plano verbal, seria o prolongamento e resultado indireto destes fenômenos primitivos.

Contudo, entre o realismo moral espontâneo dos primeiros anos e o realismo moral teórico, háum intermediário essencial a considerar: é o julgamento que a criança faz não mais a respeito de seus próprios atos, mas a respeito da conduta de seus semelhantes próximos.

No que se refere a si mesma, a criança consegue muito depressa (por volta dos três ou quatro anos) diferen- ciar as faltas intencionais e as infrações involuntárias no código das regras morais. Logo aprende a se desculpar, invocando "feito não de propósito". No que se refere aos atos dos seus semelhantes próximos (crianças concretas), as coisas se apresentam de modo muito diferente. De um modo geral, a criança é muito mais severa para com os outros do que para consigo mesma e apresenta um julgamento severo das faltas alheias.

A razão dessa segunda atitude é que a conduta alheia aparece para a criança na sua materialidade, muito antes de ser compreendida em sua intencionalidade (responsabilidade subjetiva). Assim, ela é levada a confrontar imediatamente a materialidade com a regra estabelecida e a julgar os atos segundo esse critério essencialmente objetivo. Seria por um esforço de contínua simpatia e de generosidade que a criança resiste, assim como nós mesmos, a tal tendência e procuramos compreender as reações de outrem em função da intenção.

Com a avaliação da conduta dos semelhantes (casos intermediários), nos aproximamos à situação um pouco artificial na qual a criança considera atos, não observados diretamente, mas descritos por meio de uma história, o que seria o caso da pesquisa realizada por Piaget sobre o julgamento moral na criança.

Se o realismo moral dura muito mais tempo no que se refere aos julgamentos a respeito dos semelhantes do que no domínio puramente individual, é claro que ele se prolongará ainda mais no que se refere aos exemplos inteiramente verbais contidos nas histórias apresentadas.

Desse modo, para Piaget (1932/1994, p. 146), a tomada de consciência implicada por toda reflexão teórica não repete somente, com um atraso mais ou menos prolongado, o que se passou efetivamente na prática dos atos; há, além disso, atrasos e deformações inerentes ao próprio mecanismo da reflexão.

De fato, desde que à ação direta sucede ou se sobrepõe um pensamento destacado do real e libertado pelo poder da palavra ou da imaginação, o espírito deixa-se dominar por um conjunto de ilusões de perspectiva e, em particular, pela perspectiva inconsciente do egocentrismo (centração no próprio ponto de vista). Como o autor mostra em outros estudos (Piaget, 1945/1973b, 1936/1987), no domínio intelectual, a criança que raciocina no plano verbal enfrenta uma série de dificuldades vencidas, há muito tempo, pela inteligência prática. Da mesma forma, no domínio moral, deixar-se-á conduzir, em relação às narrações simplesmente ouvidas, a uma série de julgamentos, sem compaixão e sem compreensão psicológica, demostrando, dessa forma, um realismo moral mais ou menos sistemático, quando, na vida real, simpatizaria, sem dúvida alguma, com aqueles que, de longe, considera como grandes culpados (Piaget, 1932/1994, pp. 146-147).

Dessa forma, o realismo moral espontâneo dos primeiros anos, embora se atenue progressivamente no que se refere à própria conduta, pode muito bem desenvolverse (atenuar-se) primeiramente na avaliação dos atos dos semelhantes e, finalmente, na reflexão relativa aos casos 
inteiramente teóricos evocados pelas narrações, pelas histórias contadas.

Em conclusão, o realismo moral expresso nos julgamentos sobre terceiros corresponde realmente a algo de efetivo e de espontâneo do pensamento infantil. Esse realismo pode estar vencido no plano da ação prática, mas não no plano da reflexão.

Por que o realismo moral perdura muito tempo e é difícil de ser vencido, no plano da reflexão verbal, pela moral do bem?

Como foi dito anteriormente, toda regra, quer seja imposta pelo mais velho ao caçula ou pelo adulto à criança, começa por ficar exterior à consciência antes de ser aceita como um bem necessário às relações sociais que excluem a submissão à autoridade. Durante esta fase, o realismo moral mais rigoroso pode muito bem aliar-se à prática aparentemente mais moderada e mais egocêntrica.

Com efeito, o egocentrismo espontâneo e inconsciente da criança e a coação adulta, longe de constituírem a exata antítese um do outro, combinam-se, ao contrário, até darem nascimento a compromissos paradoxais. É o caso da criança que se mostra muito severa com a mentira dos semelhantes, mas ela mesma falta com a verdade tranquilamente, na ação prática. É menos grave a falta de uma criança que mentiu à mãe para lograr dela um prêmio que aquela atitude onde a criança exagerou um acontecimento: "ter visto um cachorro igual a uma vaca".

A coação reforça os traços próprios ao egocentrismo e da responsabilidade objetiva. Somente a cooperação pode libertar as crianças, ao mesmo tempo do egocentrismo e o dos resultados da coação e, dessa maneira, possibilitar o desenvolvimento dos sentimentos de afeição mútua e de confiança mútua e com isso a consideração das intenções e de todas as condições atenuantes da falta moral. Somente a cooperação pode possibilitar o desenvolvimento dos sentimentos de generosidade e consideração real pelo próximo.

\section{A relação entre prática e a teoria na formação da moral do bem}

Se o realismo moral, quando dos primeiros intentos da reflexão teórica da criança, prolonga o realismo moral da ação prática inicial, a moral do bem, que fundamenta a autonomia moral, prolonga também alguma relação prática inicial, que se impõe progressivamente na vida moral da criança? A moral do bem, que se exprime no plano da reflexão teórica, resulta de um processo de tomada de consciência da ação prática?

A moral do dever, sobre a sua forma original, é essencialmente heterônoma, pois o bem é obedecer à vontade do adulto e o mal é agir por conta própria. Não há lugar, numa tal moral, para a moral do bem, embora este seja um ideal mais espontâneo da consciência da criança e a mais atraente, por não ser coercitivo. As relações da criança com o seu meio ambiente social não se restringem às relações de coação e respeito unilateral; existe nas suas ações espontâneas necessidade de afeição mútua que a impele, desde o começo, a atos de generosidade e mesmo de sacrifício que não estão prescritos e codificados socialmente. Existem muitas passagens na vida afetiva da criança, nas quais ela mostra sentimentos que a impelem proteger e vingar outras crianças que sofrem atropelos dos colegas.

Para Piaget, aí se encontra, sem dúvida nenhuma, o ponto de partida da moral do bem, que veremos desenvolver-se à margem daquela do dever e que triunfará completamente em alguns indivíduos, na medida em que estes pratiquem a simpatia e o respeito mútuo. Como estas ações se realizam apenas nas relações de cooperação, pode-se afirmar que a moral do bem é produto da cooperação, contrariamente à moral do dever, que é produto da coação e que só poderia conduzir à hetoronomia.

Como a criança chegará à moral do bem e da autonomia propriamente dita? No campo dos valores morais ligados ao roubo e à mentira, observa-se um sinal quando a criança descobre que a veracidade e a honestidade são necessárias nas relações de simpatia e de confiança mútua. Assim, há autonomia quando a consciência considera como necessário um ideal, o de não trair a verdade, independente de qualquer pressão exterior. A autonomia só aparece com a reciprocidade, quando o respeito mútuo é bastante forte, para que o indivíduo experimente interiormente a necessidade de tratar os outros como gostaria de ser tratado. Por isso, a autonomia moral exige outra forma de relação social, a cooperação, que promova a reciprocidade no respeito e consideração.

Mas o problema que subsiste é de saber de onde surge essa necessidade de respeito mútuo e de reciprocidade. Essa necessidade se impõe como uma atitude sobreposta ao respeito unilateral, produto da transmissão social ou cultural, ou ela éproduto de uma tomada de consciência de relações primitivas na vida afetiva da criança?

É preciso dizer que, para Piaget (1932/1994, p. 296), nem as normas lógicas e nem as normas morais são inatas na consciência individual. Assim como as noções da inteligência sensório-motora, que são construídas durante os primeiros dezoito meses, os comportamentos relativos às pessoas (esquemas afetivos) se constituem desde o princípio a partir das reações afetivas, nas quais se podem encontrar as bases (o estofo) de todas as condutas morais ulteriores.

Contudo, essas relações afetivas ainda não podem ser qualificadas de morais. É preciso advertir que, assim como um ato inteligente não poderia ser qualificado de lógico, um traço de sensibilidade não poderia ser considerado de moral. Será moral a partir do momento em que algumas normas imprimam a tais matérias-primas uma dada estrutura e regras de equilíbrio (inseridas em regras internas de reciprocidade coerentes que refletem as perspectivas de dois ou mais indivíduos, como se observará na "mutualidade"das ações reciprocas). Nada permite afirmar a existência de tais normas nos comportamentos anteriores à linguagem, pois, rigorosamente, nesse plano de ação, não existem trocas de pontos de vista entre indivíduos. A moral do bem, no seu acabamento, constitui uma forma a priori na medida em que 
seu caráter obrigatório e necessário decorre gradualmente da sua própria evolução e equilíbrio progressivo. É no fim desse processo, e não no seu começo, que o espírito toma consciência das leis que lhe são imanentes. Mas, quais dessas leis the são imanentes no campo moral?

Se existe uma evolução dirigida e marcha para um equilíbrio, deve existir alguma coisa influindo desde o começo. Mas, sob que forma essa alguma coisa influi nessa evolução? Sob a forma de uma estrutura que organiza o conteúdo da consciência ou sob a forma de uma lei funcional de equilíbrio, da qual o espírito não tem consciência imediatamente e que somente se manifestará através de uma multiplicidade de estruturas a ocorrer sucessivamente? Esse a priori funcional não é um princípio nem uma estrutura, da qual o espírito possa tomar consciência, mas sim um conjunto de relações funcionais que implicam desequilíbrios e equilíbrios sucessivos (momentos de conflitos e de coerência entre os interlocutores). Essas relações funcionais constituem as relações de reciprocidade da qual o espírito toma consciência no seu acabamento.

Mas como o espírito ou o pensamento tirará desse equilíbrio funcional normas propriamente ditas? Para Piaget, isso ocorre na formação de estruturas sucessivas por meio de uma tomada de consciência também progressiva e adequada.

Basta, para que a procura funcional de organização, a qual atesta a atividade sensório-motora e afetiva original, dê nascimento a regras propriamente ditas de organização, que o próprio espírito tome consciência desta procura e de suas leis, e traduza, deste modo, em estrutura o que até aí era simples funcionamento.(1932/1994, p.297).

Como ocorre a tomada de consciência das leis de reciprocidade no campo moral?

A moral do bem, como forma de equilíbrio superior da consciência do indivíduo, apresenta uma diferença de natureza em relação à moral do dever: onde a segunda leva ao reconhecimento de normas heterônomas, a primeira, com o respeito mútuo, para o qual não existe outra lei que sua própria mutualidade, conduz à constituição de normas interiores do seu próprio funcionamento (lei da reciprocidade).

A criança começa a praticar, sem mais, a reciprocidade (respeito mútuo), o que não é tão fácil como se poderia supor. Depois, uma vez que está habituada a essa forma de equilíbrio das ações, ocorre uma espécie de repercussão da forma sobre o conteúdo (reflexão sobre suas próprias coordenações de ações ou sobre as ações do respeito mútuo). Não são mais os comportamentos recíprocos considerados como justos, mas essencialmente os comportamentos suscetíveis de reciprocidade indefinida (universais e necessários). No caso da justiça, o preceito: 'Não faças aos outros o que não queres que te façam' sucede, assim, à igualdade brutal. A criança coloca o perdão acima da vingança, não por fraqueza, mas porque com a vingança 'não terminaríamos nunca' (menino de dez anos) (Piaget, 1932/1994, p. 242).
Essa mutualidade é expressa por Piaget em termos mais simples:

Se A respeita $B$ e reciprocamente, éporque A primeiramente foi respeitado por $B$, depois ele próprio situou-se no ponto de vista de B. Está aí uma operação completamente nova em relação ao respeito simples: se B se limitar a respeitar A para sempre, $\mathrm{B}$ reconhecerá como valores todas as ordens de $\mathrm{A}$, por mais arbitrárias que possam ser e estranhas às leis da reciprocidade. Pelo contrário, desde que A se identifique moralmente com B e submeta, assim, seu próprio ponto de vista às leis de reciprocidade, os produtos deste respeito mútuo só poderiam ser novos, porque as normas reconhecidas agora permanecem necessariamente interiores a essa mesma reciprocidade.

Assim, o sentimento do bem resultará da tendência que impele os indivíduos a se respeitarem e se situarem mental e sentimentalmente - na perspectiva dos outros. $O$ fator constituinte da moral do bem é, portanto, a própria lei de reciprocidade de sentimentos ou de afeição mútua entre iguais.

Mas, como se explica o atraso da tomada de consciência da moral do bem em relação à moral do dever?

É importante lembrar que assim como na moral do dever a responsabilidade objetiva pode muito bem estar ultrapassada há muito tempo no plano da ação e subsistir ainda no plano do pensamento; na moral do bem, a afeição recíproca pode estar atrasada no plano da consciência e reflexão, mas não no plano da ação. Além disso, as crianças mais novas são mais tolerantes ao justificar as próprias faltas e justificam suas ações levando em conta as intenções (não fazer de propósito); logo a seguir, na avaliação das faltas dos colegas mais próximos se tornam menos rigorosos que em relação de semelhantes hipotéticos. Assim, as crianças podem, progressivamente, ser mais tolerantes e solidárias com os seus colegas próximos, podem aceitar as suas dificuldades e se colocar na situação deles por afeição recíproca, antes de compreender essas mesmas ações em relação a crianças hipotéticas.

Desse modo, a superação da responsabilidade objetiva ocorre na medida em que ocorre o desenvolvimento das relações de afeição recíproca. Mas, por que o atraso dessa última? Pela presença do adulto e a atitude inicial da criança em se submeter incondicionalmente à autoridade do adulto. A contradição nascente entre as primeiras exigências de afeição recíproca e o respeito unilateral ocorre justamente por causa dessa situação paradoxal. Geralmente é a segunda que vence a primeira. Somente quando o avanço do exercício da reciprocidade tornar forte a exigência do respeito mútuo é que os imperativos da moral do dever serávencida.

\section{Condições para a tomada de consciência moral e suas implicações pedagógicas}

Este estudo evidencia que o discurso e a reflexão moral se relacionam com as primeiras atitudes práticas da criança: o realismo moral teórico está relacionado com 
as primeiras atitudes práticas da criança, com o realismo moral primitivo, as quais resultam da atitude espontânea da criança e das regras transmitidas pelo adulto; a norma moral autônoma também está relacionada à atitude prática da criança, não de sentir obrigação com a regra imposta pelo adulto, mas, sim, da necessidade de afeição mútua. Isso significa que a aceitação ulterior da norma como bem moral não depende simplesmente da transmissão, mas, sim, e principalmente, da tomada de consciência das regras de reciprocidade envolvidas nos sentimentos de afeição mútua.

A tomada de consciência não é uma simples tradução, no plano da representação, da prática inicial, mas, sim, o seu prolongamento com reconstrução progressiva. As coordenações realizadas na ação prática (afeição mútua, respeito mútuo, ações altruístas, etc.) são organizadas e reorganizadas no plano da representação e da consciência quando elas são defendidas e justificadas, quando das soluções (resultados) dadas aos conflitos se parte para as razões delas. Nesse processo, de prática e reflexão, se poderá alcançar, progressivamente, as formas necessárias e universais de reciprocidade. Nesse sentido, a tomada de consciência da ação prática apresenta problemas difíceis de superar de imediato. O egocentrismo e a coação adulta, antes de promover a tomada de consciência adequada das ações consolida uma aceitação passiva das regras imposta pelos adultos (acomodação sem assimilação), o que torna exterior à consciência a regra adquirida. Assim, há um respeito místico e rigoroso da regra, mas, ao mesmo tempo, uma prática egocêntrica dela. A possibilidade da tomada de consciência do verdadeiro valor da regra depende do fortalecimento das relações de reciprocidade e não da obediência cega à autoridade ou à tradição societária. Portanto, depende do exercício das relações de solidariedade e de cooperação entre iguais.

Se a análise anterior for verdadeira, não existe outro modo de promover a evolução do processo de tomada de consciência senão através da experiência concreta de relações de reciprocidade e de cooperação. Portanto, a primeira condição primordial da evolução da moral é a vida social da criança. Contudo, a vida social não pode ser reduzida à relação passiva de recepção de normas sociais, mas, sim, entendida como troca e interação entre iguais. Desse modo, a cooperação se constitui como a mola propulsora do desenvolvimento da vida moral e do conhecimento (Piaget, 1973a).

Se a evolução da moral obedece às relações sociais de cooperação, esta noção não se reduz àsua dimensão intelectual, pois a cooperação moral tem um significado específico, embora solidário com a anterior. Com efeito, se a cooperação intelectual exige discussão e o confronto de pontos de vista na verificação objetiva, a cooperação moral exige algo mais que isso: requer comparação mútua das intenções íntimas e das regras que cada um adota; conduz o indivíduo a julgar objetivamente atos e ordens de outrem, incluindo os adultos; exige saber colocar-se no lugar do outro na troca de sentimentos e pensamentos. Somente nessas experiências poderiam vingar e se destacar as leis funcionais da evolução das ações morais: as leis da reciprocidade e afeição mútua. Por isso, o desenvolvimento intelectual não acarreta necessariamente o desenvolvimento moral.

Em resumo, a tomada de consciência que conduz à moral autônoma exige as seguintes condições básicas:

Em primeiro lugar, o indivíduo por si só não écapaz de tomar consciência das normas de conduta e constituir normas propriamente ditas. A vida social é absolutamente necessária para permitir ao indivíduo tomar consciência do funcionamento do espírito e para transformar os simples equilíbrios funcionais imanentes a toda atividade mental em normas propriamente ditas.

Em segundo lugar, as relações de respeito unilateral e de coação, que se estabelecem entre o adulto e a criança, contribuem para a constituição de um primeiro tipo de controle lógico e moral de caráter heterônomo. O problema é que esse primeiro tipo de controle não poderia bastar para eliminar o egocentrismo infantil e constituir a verdadeira moralidade. Segundo Piaget (1932/1994, p. 299),

para que uma conduta possa ser qualificada de moral, é preciso mais que um acordo exterior com conteúdo das regras admitidas: convém, ainda, que a consciência tenda para a moralidade como um bem autônomo e seja capaz, ela mesma, de apreciar o valor das regras que the propomos.

Ora, no caso do respeito unilateral, o bem não é nada mais que o que está de acordo com os imperativos heterônomos.

Em terceiro lugar, a cooperação é forma primordial de troca social que promove a tomada de consciência das normas de reciprocidade. Contudo, é preciso distinguir a cooperação no campo intelectual e moral.

$\mathrm{Na}$ vida intelectual, a cooperação é fonte de crítica e da tomada de consciência das normas lógicas inerentes na atividade individual e coletiva (coordenação das ações individuais e sociais). No campo intelectual, o controle mútuo repele simultaneamente a crença espontânea própria ao egocentrismo e a confiança cega na autoridade adulta. A discussao produz, assim, a reflexão e a verificação objetiva. Nessa medida, a cooperação permite o reconhecimento dos princípios da lógica enquanto leis normativas necessárias à pesquisa comum; permite, sobretudo, a tomada de consciência da lógica das relações, das leis de reciprocidade e da perspectiva.

No que se refere às realidades morais, a cooperação é fonte de crítica e de superação do egocentrismo. É ela que, pela comparação mútua das intenções íntimas e das regras que cada um adota, conduz o indivíduo a julgar objetivamente atos e ordens de outrem, incluindo os adultos. A cooperação repele ao mesmo tempo o egocentrismo e o realismo moral (regra exterior à consciência). Como resultado disso, a regra deixa de ser exterior à consciência e é admitida como um bem que independe do mandato da autoridade. A regra moral de não mentir se interioriza e se constitui como um bem que garante a confiança mútua. $A$ consciência do bem resulta da aceitação das normas de 
reciprocidade - necessidade de tratar os outros como gostaria de ser tratado -que se tornaram suficientemente fortes para vencer tanto o egocentrismo como o realismo moral.

Por outro lado, concordamos com Piaget, quando ele se refere aos achados da pesquisa psicológica e sociológica. Segundo ele, embora as descobertas da pesquisa psicológica sejam absolutamente importantes para a prática e a teoria pedagógica, elas não se prolongam imediatamente em boas práticas pedagógicas. Esses achados exigem serem testados e desenvolvidos nas experiências pedagógicas concretas. Contudo, em nossa opinião, consideramos impossível deixar de considerá-los quando se trata de propostas pedagógicas inovadoras que colocam os alunos como seres ativos e dignos de respeito. As experiências pedagógicas que visam ao exercício democrático e aos princípios republicanos não poderiam deixar de colocar em prática "trabalhos de grupos"e de "autogoverno", os quais não somente promovem a socialização da criança, mas também o desenvolvimento da reciprocidade moral.

A tomada de consciência no desenvolvimento moral é importante para o trabalho educativo e pedagógico. A passagem das coordenações práticas para coordenações conceituadas exige certas condições necessárias: diante dos conflitos de relacionamentos inter-individuais é preciso que os sujeitos reconstituam - através de relatos orais - as ações próprias em relação aos outros e reciprocamente, que procurem compreender os motivos das ações dos outros de um modo descentrado, que se disponham a ouvir o ponto de vista dos outros. Num projeto educativo ou pedagógico que se propõe efetivamente promover sujeitos autônomos moralmente - sujeitos que atuam pelo bem moral - o diálogo deverá partir dos resultados da prática moral para a análise dos motivos ou razões que os levaram ao conflito ou ao acordo mútuo. Isso entre dois indivíduos ou num grupo maior (sala de aula, a classe ou instituição escolar como um todo). Assim, os projetos de educação moral para a autonomia deverão deixar de ser verbalistas e centradas nos imperativos da autoridade adulta (pais e professores) e se constituir, pelo contrário, em ambientes cooperativos onde os conflitos possam ser discutidos livremente, como ocorre numa convivência democrática nas sociedades "orgânicas". A simples prática da regra não produz o desenvolvimento da moral autônoma, assim como o discurso do "bem moral" não produz um sentimento moral autêntico.

\section{Referências}

Bronzatto, M. \& Camargo, R.(2010). Moral e afetividade em Piaget: os "movimentos íntimos da consciência" em O juízo Moral na Criança. Shème, 3 (5), 80-109.

Conti, L. F. (2015). Prática e consciência da regra no jogo de "Bola queimada": contribuição para a educação física. Tese de doutorado, Universidade Estadual Paulista, Marília-SP.

Ducret, J. J. (1984). Jean Piaget: savant et philosophe; les années de formation, 1907-1924; étude sur la formation des connaissances et du sujet de la connaissance. Genève : Droz.

Freitag, B. (1990). Razão teórica e razão prática: Kant e Piaget. ANDE; Revista da Associação Nacional de Educação, 9 (15), 5568.

Freitag, B. (1991). Piaget e a Filosofia. São Paulo: UNESP.

Freitag, B. (1992). Itinerários de antigona; a questão da moralidade. Campinas: Papirus.

Freitas, L. (2003). A Moral na obra de Jean Piaget: um projeto inacabado. São Paulo: Cortez.

La Taille, Y. (2006). A importância da generosidade no início da gênese da moralidade na criança. Psicologia: Reflexão e Crítica, 19 (1), 9-17.

Lemos de Souza, L. \& Vasconcelos, M. S. (2009). Juízo e ação moral: desafios teóricos em Psicologia. Psicologia e Sociedade, 21.(3), $343-352$

Piaget, J. (1918). Recherche. Lausanne: La Concorde.

Piaget, J. (1927). Le respecte de la règle dans les sociétés d'enfants. Le Nouvel Essor, 22(23).

Piaget, J. (1930). Le développement de l'esprit de solidarité chez l'enfant et la notion de justice chez l'enfant. In: Comment faire connaître la Societé des Nations et développer l'esprit de cooperation international: troisième cours pour le personnel enseigment. Bureau International d'Éducation (pp. 52-57). Genéve: BIE.

Piaget, J. (1931). I'esprit de solidaritéchez l'enfant et la collaboration internationale. In: Recuil Pedagogique,2(1), 11-27.

Piaget, J. (1934): Une éducation pour la paix est-elle possible? In: Bulletin de L'Enseignement de la Societédes Nations, (1), 17-23.

Piaget, J. (1998a). A educação da Liberdade. Em S. Parrat \& A. Tryphon (Orgs.), Jean Piaget sobre Pedagogia. Textos inéditos (pp. 153-159).São Paulo: Casa do Psicólogo.

Piaget, J.(1998b). O desenvolvimento moral do adolescente em dois tipos de sociedade: sociedade primitiva e sociedade "moderna". Em S. Parrat \& A. Tryphon (Orgs.), Jean Piaget sobre Pedagogia. Textos Inéditos(pp. 161-166). São Paulo: Casa do Psicólogo.

Piaget, J. (1973a). Estudos sociológicos. (R. Di Piero, Trad.) Rio de Janeiro: Forense. (Trabalho original publicado em 1965).

Piaget, J. (1973b). A formação do símbolo na criança. Rio de janeiro: Guanabara/Koogan. (Trabalho original publicado em 1945).

Piaget, J. (1977). A tomada de consciência. (E.B. Souza, trad.) São 
Paulo: Melhoramentos/ USP. (Trabalho original publicado em 1974).

Piaget, J. (1978). Fazer e compreender. (C.L. de Paula, trad.). São Paulo: Melhoramentos/USP (Trabalho original publicado em 1974).

Piaget, J. (1995). Abstração reflexionante. ( F. Becker/ P.B. Gonçalves da Silva, trad.), Porto Alegre: Artes Médicas. (Trabalho original publicado em 1977).

Piaget, J. (1987). O nascimento da Inteligência na criança. (A. Cabral, Trad.) Rio de Janeiro: Guanabara. (Trabalho original publicado em 1936).
Piaget, J. (1994). O juízo moral na criança. (E. Lenardon, Trad.) São Paulo: Summus. (Trabalho original publicado em 1932).

Vidal, F. (1994). Piaget before Piaget. Massachusset/ London: Harvard University Press.

Vonèche, J. (1992). La Première théorie de l'equilibre de Jean Piaget (1981). Em D. Maurice \& J. Montangero (Orgs.), Équilibre et équilibration dans l'oeuvre de Jean Piaget et au regard de courants actuals (pp. 11-29). Genève: Fondation Archives Jean Piaget.

Recebido em: 27/02/2016

Reformulado em: 21/11/2016

Aprovado em: 19/12/2016

\section{Sobre o autor}

Adrián Oscar Dongo Montoya (dongomontoya@hotmail.com)

Orientador de Doutorado. Doutorado em Psicologia Escolar e do Desenvolvimento Humano pela Universidade de São Paulo, (1988).

Professor Titular da Universidade Estadual Paulista Júlio de Mesquita Filho, Brasil. 